\title{
Roles of Heterotrimeric GTP-Binding Proteins in the Progression of Heart Failure
}

\author{
Motohiro Nishida ${ }^{1, *, \S}$ \\ ${ }^{1}$ Department of Pharmacology and Toxicology, Graduate School of Pharmaceutical Sciences, Kyushu University, \\ 3-1-1 Maidashi, Higashi-ku, Fukuoka 812-8582, Japan
}

Received March 30, 2011; Accepted June 6, 2011

\begin{abstract}
Heart failure is a major cause of death in developed countries, and the development of an epoch-making cure is desired from the viewpoint for improving the quality of life and reducing the medical cost of the patient. The importance of neurohumoral factors, such as angiotensin (Ang) II and catecholamine, for the progression of heart failure has been supported by a variety of evidence. These agonists stimulate seven transmembrane-spanning receptors that are coupled to heterotrimeric GTP-binding proteins (G proteins). Using specific pharmacological tools to assess the involvement of $\mathrm{G}$ protein signaling pathways, we have revealed that $\alpha$ subunit of $\mathrm{G}_{\mathrm{q}}\left(\mathrm{G} \alpha_{\mathrm{q}}\right)$ activates $\mathrm{Ca}^{2+}$-dependent hypertrophic signaling through diacylglycerol-activated transient receptor potential canonical (TRPC) channels (TRPC3 and TRPC6: TRPC3/6). In contrast, activation of $\mathrm{G}_{12}$ family proteins in cardiomyocytes confers pressure overload-induced cardiac fibrosis via stimulation of purinergic $\mathrm{P}_{2} \mathrm{Y}_{6}$ receptors induced by extracellular nucleotides released from cardiomyocytes. In fact, direct or indirect inhibition of TRPC $3 / 6$ or $\mathrm{P}_{2} \mathrm{Y}_{6}$ receptors attenuates pressure overload-induced cardiac dysfunction. These findings will provide a new insight into the molecular mechanisms underlying pathogenesis of heart failure.
\end{abstract}

Keywords: heart failure, fibrosis, $G$ protein, transient receptor potential channel, purinergic $\mathrm{P}_{2} \mathrm{Y}_{6}$ receptor

\section{Introduction}

Heart failure is a final stage of every cardiovascular disease, including chronic hypertension, aortic stenosis, and myocardial infarction. In an early stage of heart failure, the heart changes its structure and morphology (remodeling) to adapt itself from hemodynamic overload. However, progression of cardiac remodeling, including cardiomyocyte hypertrophy and collagen deposition (fibrosis), adversely promotes myocardial stiffness and left ventricular dilation, resulting in progression of heart failure (1). Thus, preventing the progression of cardiac remodeling is expected to suppress the progression of heart failure. As hyperfunctions of sympathetic nerve

*Corresponding author. nishida@phar.kyushu-u.ac.jp Published online in J-STAGE on August 6, 2011 (in advance) doi: 10.1254/jphs.11R05CP system and renin-Ang II-aldosterone system have been implicated in the progression of heart failure, hormonal disorder is thought to be a primary cause of heart failure.

G protein-coupled receptors (GPCRs) are a conserved family of seven transmembrane spanning receptors that occupy the majority of receptors in the genome, and about $40 \%$ of the drugs used for therapeutic treatment all over the world may directly or indirectly target GPCRs (2). Although it has been estimated that 200 kinds of GPCRs are expressed in the myocardium, most of the therapeutic drugs for the heart failure target only 2 receptors, $\beta_{1}$ adrenergic receptor $\left(\beta_{1} \mathrm{AR}\right)$ and angiotensin (Ang) II type 1 receptor $\left(\mathrm{AT}_{1} \mathrm{R}\right)$. However, the blockers against $\beta_{1} \mathrm{AR}$ and $\mathrm{AT}_{1} \mathrm{R}$ are not necessarily sufficient for the treatment of heart failure patients. Thus, researchers have explored the underlying molecular mechanisms of heart failure in the hopes of identifying novel therapeutic tar-

${ }^{\S}$ This review article is written on the occasion of the author receiving the 26th Award for Encouragement of Young Investigators from The Japanese Pharmacological Society in 2011 and on the basis of the targeted work. 
gets, including GPCR(s) and the components that participate in GPCR signaling pathways in failing hearts (3).

\section{Pharmacological assessment of $G$ protein signaling pathways}

$\mathrm{G}$ proteins form a heterotrimer comprised of $\alpha, \beta$, and $\gamma$ subunits at the resting state. The activated form of the receptor can catalyze the exchange of GTP for GDP bound to the $\alpha$ subunit $(\mathrm{G} \alpha)$ of specific $\mathrm{G}$ protein, leading to dissociation of $\mathrm{G} \alpha$ from the $\beta \gamma$ dimer $(\mathrm{G} \beta \gamma)$. Both $\mathrm{G} \alpha$ and $\mathrm{G} \beta \gamma$ couple with the respective effectors to activate the independent signaling pathways. The $\mathrm{G} \alpha$ has an intrinsic GTPase activity to hydrolyze GTP into GDP, and GTP hydrolysis will terminate the activation of $\mathrm{G}$ protein signaling. The conformation switch between the GDP-bound state and GTP-bound state is called the "G (protein) cycle" (Fig. 1).

G proteins are classified into four families $\left(\mathrm{G}_{\mathrm{s}}, \mathrm{G}_{\mathrm{i}}, \mathrm{G}_{\mathrm{q}}\right.$, $\mathrm{G}_{12}$ ) on the basis of amino acid sequence similarity and the functional difference of an effector molecule activated by $\mathrm{G} \alpha$. Activation of each $\mathrm{G}$ protein signaling can be evaluated by the production of second messenger through activation of its effector enzyme. Commercial toxins or reagents that activate or inactivate the specific $\mathrm{G}$ protein signaling have become able to evaluate easily the involvement of $\mathrm{G}$ protein in various cellular functions. However, attention will be required for the interpretation of the results obtained using these toxins. In fact, we found that Pertussis toxin (PTX), which ADPribosylates $\mathrm{G} \alpha_{\mathrm{i}}$ and uncouple receptors from $\mathrm{G}_{\mathrm{i}}$, stimulates toll-like receptor 4 that leads to an increase in the number of $\mathrm{AT}_{1} \mathrm{Rs}$ (4). In order to overcome these problems, biological approaches to inhibit the function of a specific $\mathrm{G}$ protein have been conducted. For example, overexpression of each carboxyl-terminal region of $\mathrm{G} \alpha$
(G $\alpha$-ct) can induce subtype-specific inhibition of $\mathrm{G}$ protein signaling by the competition of corresponding $\mathrm{G} \alpha$ to couple with receptors $(5,6)$. In addition to $\mathrm{G} \alpha$-ct, there is another tool to specifically inhibit $\mathrm{G} \alpha$-mediated signaling. Regulator of $G$ protein signaling (RGS) proteins function as GTPase-activating protein (GAP) of G proteins, which promotes the inactivation of $G$ proteins. Thus, an RGS domain polypeptide specifically inhibits one or more $\mathrm{G} \alpha$-mediated signaling pathways. There are four tools to inhibit $\mathrm{G} \beta \gamma$-mediated signaling. Among them, a carboxyl-terminal region of $\beta$-adrenergic receptor kinase 1 [ $\beta$ ARK-ct, $\beta$ ARK is also called G proteincoupled receptor kinase 2 (GRK2)] specifically inhibits $\mathrm{G} \beta \gamma$-mediated signaling (7). In addition, activator of $\mathrm{G}$ protein signaling (AGS) 8 is reported to promote a $\mathrm{G} \beta \gamma$ dependent signal (8), and nucleoside diphosphate kinase (NDPK), which induces phosphorylation of the His ${ }^{266}$ residue of $\mathrm{G} \beta$ to form a signal complex with $\mathrm{G} \beta \gamma$, promotes $\mathrm{G} \alpha_{\mathrm{s}}$-mediated cAMP production without receptor stimulation, resulting in enhancement of cardiac muscle contractility (9). Thus, AGS8 and NDPK can also be a tool to activate $\mathrm{G}$ protein signaling pathways by inhibiting heterotrimer formation of $\mathrm{G} \alpha$ with $\mathrm{G} \beta \gamma$.

\section{Roles of $G$ proteins in the progression of heart failure}

Results of the studies using transgenic and $\mathrm{KO}$ mice have revealed that $\mathrm{G}_{\mathrm{s}}$ protein participates in positive inotropic and chronotropic effects induced by $\beta$ AR stimulation and $\mathrm{G}_{\mathrm{i} / \mathrm{o}}$ proteins participate in a negative chronotropic effect induced by muscarinic $\mathrm{M}_{2}$ receptor stimulation (10). On the other hand, neurohumoral factors, such as Ang II, endothelin (ET)-1, and catecholamine, induce structural changes of the heart and cardiac dysfunction through activation of $\mathrm{G}_{\mathrm{q}}$ and $\mathrm{G}_{12}$ family protein signaling

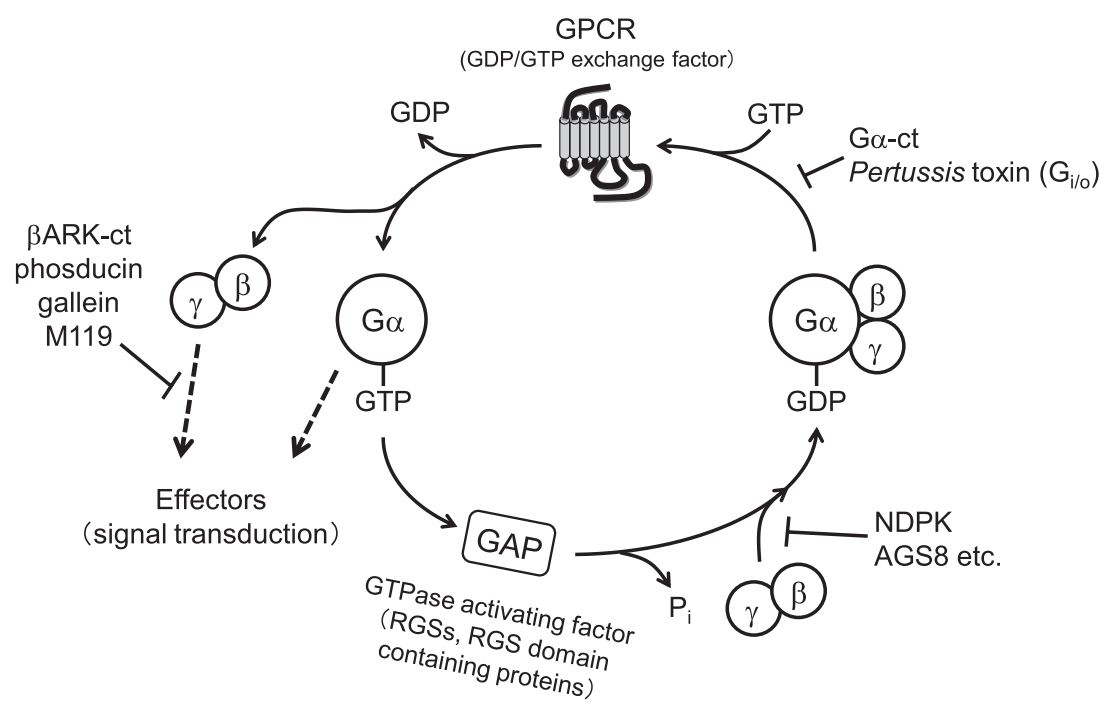

Fig. 1. G protein cycle and its regulators. $\beta \mathrm{ARK}$ : $\beta$-adrenergic receptor kinase, RGS: regulator of $\mathrm{G}$ protein signaling, AGS: activator of $\mathrm{G}$ protein signaling, NDPK: nucleoside diphosphate kinase. 
pathways. Here, I will introduce recent our findings about the pathophysiological role of each $G$ protein family in heart failure.

\subsection{Diacylglycerol-activated TRPC channels contrib- ute to $\mathbf{G} \alpha_{\mathbf{q}}$-mediated cardiac hypertrophy}

Several $\mathrm{G}_{\mathrm{q}}$ protein-coupled receptor agonists, such as Ang II, ET-1, and catecholamine, are known to induce hypertrophic gene expression through $\mathrm{Ca}^{2+}$-dependent signaling pathways. The mechanism of $\mathrm{Ca}^{2+}$-mediated hypertrophy was first suggested by Molkentin et al. that a $\mathrm{Ca}^{2+}$-dependent transcription factor, nuclear factor of activated T cells (NFAT), mediates $\mathrm{G} \alpha_{\mathrm{q}}$-mediated cardiac hypertrophy through increases in intracellular $\mathrm{Ca}^{2+}$ concentration $\left(\left[\mathrm{Ca}^{2+}\right]_{i}\right)(11)$. Although a variety of evidence using transgenic and knockout mice have suggested that the $\mathrm{G} \alpha_{\mathrm{q}}$-mediated $\mathrm{Ca}^{2+}$ signaling pathway plays a central role in the development of hypertrophy, it is still unclear how $\mathrm{G} \alpha_{\mathrm{q}}$-mediated signaling specifically encodes the alteration of $\left[\mathrm{Ca}^{2+}\right]_{\mathrm{i}}$ on the background of the rhythmic $\left[\mathrm{Ca}^{2+}\right]_{\mathrm{i}}$ increases required for contraction. In non-excitable cells, inositol-1,4,5-trisphosphate $\left(\mathrm{IP}_{3}\right)$ produced by PLC-mediated hydrolysis of phosphatidylinositol-4,5bisphosphate is believed to predominantly regulate agonist-induced NFAT activation. However, diacylglycerol (DAG), but not $\mathrm{IP}_{3}$, was responsible for Ang II-induced NFAT activation in excitable rat cardiomyocytes (12). The DAG-sensitive inward currents were actually activated by Ang II stimulation in cardiomyocytes via an $\mathrm{IP}_{3}$-independent pathway. Membrane potential recording from single cardiomyocytes demonstrated that Ang II increased the frequency of action potentials in a DAGdependent manner. These results indicate that the DAG- mediated cation influx contributes to Ang II-induced membrane depolarization, leading to increase in the frequency of $\mathrm{Ca}^{2+}$ transients via activation of voltage-dependent $\mathrm{Ca}^{2+}$ channels, resulting in NFAT activation. Transient receptor potential canonical (TRPC) subfamily channels are a putative molecular candidate for receptoractivated cation channels (13). The I-V relationship of Ang II-induced currents supported the evidence that the currents are TRPC-like. TRPC channels have been originally proposed as store-operated channels activated by $\mathrm{Ca}^{2+}$ depletion of stores, while closely related TRPC3, TRPC6, and TRPC7 showed activation sensitivity to the membrane-delimited action of diacylglycerol (DAG). We have found that TRPC3 and TRPC6, but not TRPC7, participate in agonist- and mechanical stretch-induced cardiomyocyte hypertrophy in vitro (14). In fact, chronic treatment with a novel TRPC3-selective inhibitor after surgical transverse aortic constriction suppressed pressure overload-induced cardiac hypertrophy in vivo (15). Thus, TRPC $3 / 6$ proteins may assemble to form DAGactivated cation channels, which mediate the $\mathrm{G} \alpha_{\mathrm{q}}$-induced cardiac hypertrophy (Fig. 2). Although physiological roles of TRPC3/6 channels are still unknown, these results suggest that DAG-activated TRPC channels are a potential therapeutic target for the treatment of heart failure.

\subsection{Purinergic $P 2 Y_{6} R-G \alpha_{12 / 13}$ signaling triggers pres- sure overload-induced cardiac fibrosis}

As $\mathrm{G}_{12 / 13}$ proteins do not participate in the production of second messengers, such as cAMP and $\mathrm{Ca}^{2+}$ that can be detected with high sensitivity, and a specific inhibitor of $\mathrm{G}_{12 / 13}$ signaling including a toxin has not been found,

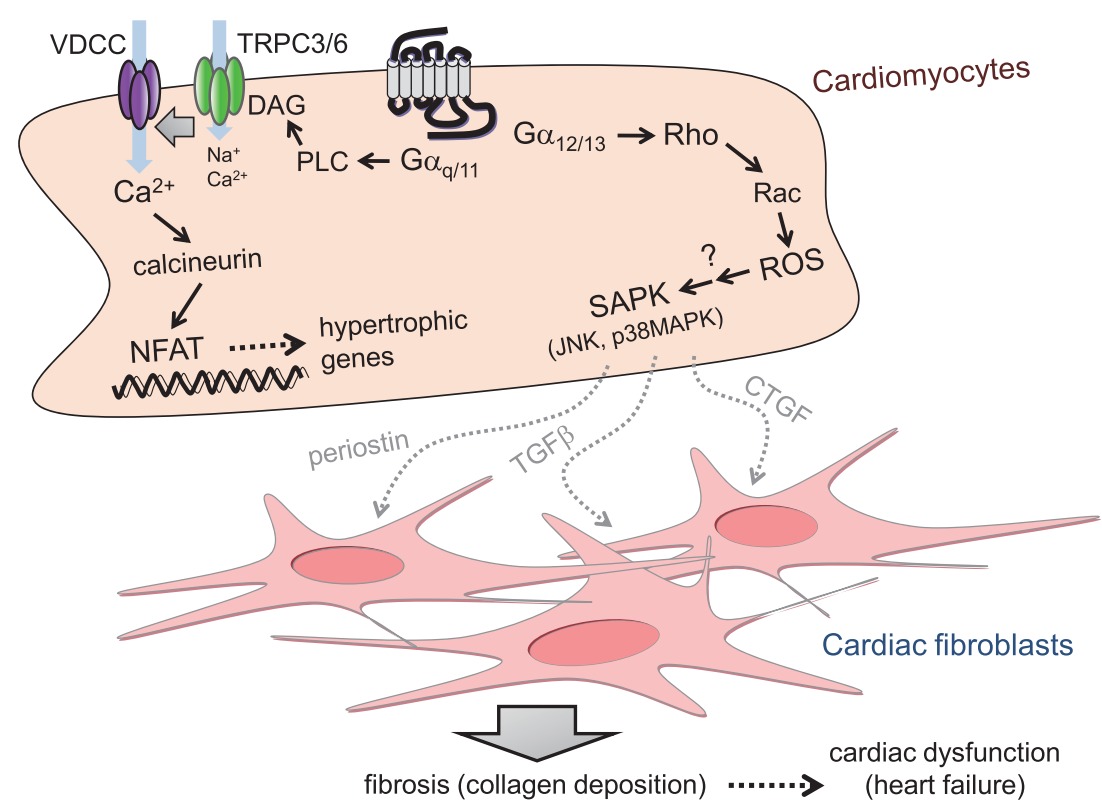

Fig. 2. Putative mechanism of $\mathrm{G}$ protein-mediated cardiac hypertrophy and fibrosis. DAG: diacylglycerol, PLC: phospholipase C, SAPK: stress-activated protein kinase, ROS: reactive oxygen species, VDCC: voltage-dependent $\mathrm{Ca}^{2+}$ channels. 
roles of $\mathrm{G}_{12}$ family proteins $\left(\mathrm{G}_{12}\right.$ and $\mathrm{G}_{13}$ : $\left.\mathrm{G}_{12 / 13}\right)$ have hardly been analyzed (10). Both activated $\mathrm{G} \alpha_{12}$ and $\mathrm{G} \alpha_{13}$ can combine with GDP/GTP exchange factor of small G protein Rho (RhoGEF), which leads to increase in Rho activity. Thus, Rho activity is thought to be the best index for evaluating the magnitude of activation of $\mathrm{G} \alpha_{12 / 13}$ signaling. Using the adenoviral gene transfer method to express $\mathrm{G} \alpha_{12 / 13}$-specifc inhibitory polypeptide (RGS domain of p115 RhoGEF: p115-RGS), we found that $\mathrm{G}_{12 / 13}$ proteins could be activated by the stimulation of $A_{1} R$, ET-1 type A receptor, or $\alpha_{1}$-adrenergic receptor in rat cardiomyocytes $(5,6,16)$. These are $\mathrm{G}_{\mathrm{q}}$ protein-coupled receptors responsible for cardiomyocyte hypertrophy, and the hypertrophic growth of cardiomyocytes induced by receptor stimulation are suppressed by p115-RGS. Activation of $\mathrm{G} \alpha_{12 / 13}$ by $\mathrm{AT}_{1} \mathrm{R}$ stimulation induces activation of small $G$ protein Rac through activation of Rho and Rho-associated coiled-coil-containing protein kinase (ROCK). In addition, Rac mediates Ang II-induced generation of reactive oxygen species (ROS) through NADPH oxidase, and generated ROS subsequently activate stress-activated protein kinase [(SAPK: c-Jun $\mathrm{NH}_{2}-$ terminal kinase (JNK) and p38MAPK)] (16). As NADPH oxidase is the only enzyme found in the downstream of the $\mathrm{G} \alpha_{12 / 13}$ proteins and the other three $\mathrm{G}$ proteins $\left(\mathrm{G}_{\mathrm{s}}, \mathrm{G}_{\mathrm{i}}\right.$, $\mathrm{G}_{\mathrm{q}}$ ) activate intracellular signaling pathways and produce respective second messengers, ROS may work as a second messenger of the $G_{12 / 13}$ protein signaling.

In contrast, pressure overload-induced cardiac hypertrophy was not suppressed in transgenic mice with cardiomyocyte-specific overexpression of p115-RGS (p115RGS-Tg). This result suggests that the molecular mechanism underlying in vitro hypertrophy induced by GPCR stimulation is different from that underlying pressure overload-induced cardiac hypertrophy in vivo. However, interstitial fibrosis and left ventricular diastolic functions were significantly attenuated by the inhibition of myocardial $\mathrm{G} \alpha_{12 / 13}$ signaling (17). In addition, transgenic mice with cardiomyocyte-specific overexpression of a constitutively active mutant of $\mathrm{G} \alpha_{13}\left(\mathrm{CA}-\mathrm{G} \alpha_{13}\right)$ have been shown to have interstitial fibrosis without accompanying cardiomyocyte hypertrophy. The pressure overload-induced activation of Rho, Rac, SAPK, and increase in the expression levels of fibrogenic factors, including transforming growth factor (TGF)- $\beta$, periostin, and connective tissue growth factor (CTGF), were remarkably suppressed in p115-RGS-Tg mice. Furthermore, we revealed that extracellular nucleotides released from cardiomyocytes through pannexin-1 hemi-channel induced by mechanical stretch induces stimulation of purinergic $\mathrm{P} 2 \mathrm{Y}_{6}$ receptor- $\mathrm{G} \alpha_{12 / 13}$ signaling in cardiomyocytes, initiating pressure overload-induced cardiac fibrosis. Although cardiac fibrosis is believed to be accompanied with $\mathrm{G} \alpha_{\mathrm{q}}$-mediated pathological hypertrophy that eventually results in heart failure, our results clearly show that cardiac fibrosis and hypertrophy are independent processes. As pannexin- 1 and $\mathrm{P} 2 \mathrm{Y}_{6} \mathrm{R}$ mRNAs in the heart are up-regulated by pressure overload, $\mathrm{G} \alpha_{12 / 13}$-mediated signaling leading to cardiac fibrosis may turn on after myocardial hypertrophy.

\subsection{Cross-talk between Ang II signaling and puriner- gic signaling}

Extracellular ATP in the cardiovascular system may be originated from various cellular sources: perivascular sympathetic nerve endings, myocytes, endothelial cells, and inflammatory cells. We revealed that nucleotides released from cardiac myocytes activate $\mathrm{P}_{2} \mathrm{Y}_{6} \mathrm{R}$ of cardiac myocytes and induce fibrotic genes. In addition, stimulation of $\mathrm{P} 2 \mathrm{Y}_{2} \mathrm{R}$ by UTP induces fibrotic responses of cardiac fibroblasts (18). Thus, extracellular nucleotides contribute to cardiac fibrosis at least two independent pathways: one is induction of fibrotic genes in cardiac myocytes through $\mathrm{P} 2 \mathrm{Y}_{6} \mathrm{R}$ and another is iNOS-mediated

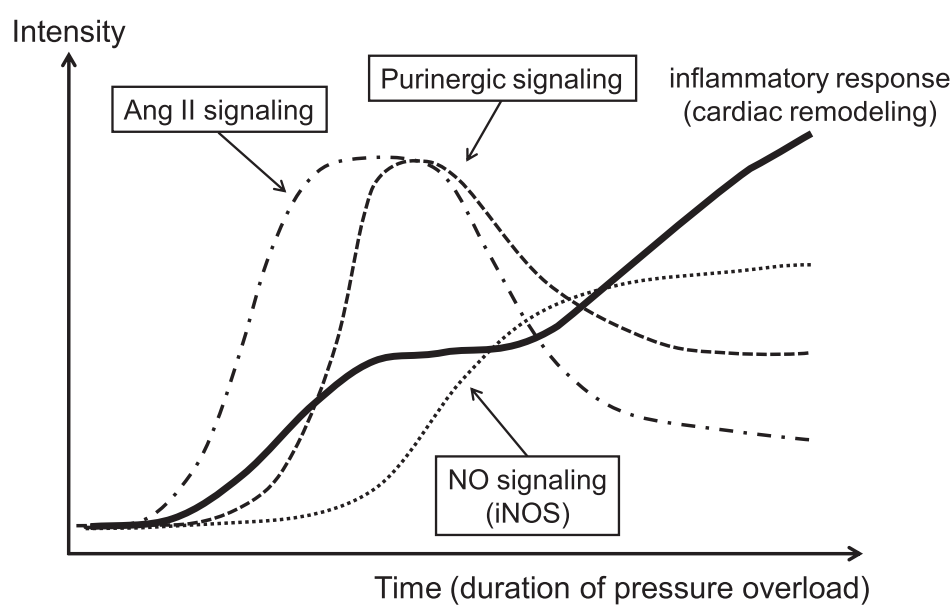

Fig. 3. Postulated function of purinergic receptor-mediated NO signaling in the progression of cardiac remodeling. In the early stage of pressure-overloaded hearts, circulatory and systemic renin-Ang systems are activated due to decrease in renal blood flow and mechanical stress of the cardiovascular system. Continuous activation of Ang II signaling may in turn stimulate purinergic signaling via increases in nucleotide release from nerve endings and densities of $\mathrm{P} 2 \mathrm{Y}_{2} \mathrm{R}$ and $\mathrm{P} 2 \mathrm{Y}_{6} \mathrm{R}(17)$, leading to heterologous down-regulation of $\mathrm{AT}_{1} \mathrm{R}$ signaling (19). Purinergic signaling may initially work as a negative regulator of Ang II signaling, but it also induces chronic inflammation through iNOS-mediated signaling pathways. 
signaling in cardiac fibroblasts through $\mathrm{P} 2 \mathrm{Y}_{2} \mathrm{R}$ (19). Although both ATP and Ang II work as an inflammatory factor, their functions in the heart seem to be different. For example, treatment with ATP markedly increases NFAT activity, but does not induce cardiomyocyte hypertrophy (20). Most recently, we have revealed that stimulation of $\mathrm{P}_{2} \mathrm{Y}_{2} \mathrm{R}$ by ATP decreases $\mathrm{AT}_{1} \mathrm{R}$ density through expression of inducible nitric oxide (NO) synthase (iNOS) (19). The iNOS-mediated NO induces covalent modification of cysteine thiol (S-nitrosylation) in nuclear factor $\kappa \mathrm{B}(\mathrm{NF}-\kappa \mathrm{B})$, leading to suppression of $\mathrm{AT}_{1} \mathrm{R}$ transcriptional activity. Thus, purinergic signaling may negatively regulate Ang II signaling through iNOS production in an early stage of heart failure, but accordingly induce chronic inflammation through activation of NO-based signaling (Fig. 3).

\section{Conclusion}

Cardiac fibrosis has been believed to be accompanied with $\mathrm{G} \alpha_{\mathrm{q}}$-mediated pathological hypertrophy that eventually results in heart failure. However, our results clearly show that cardiac fibrosis and hypertrophy are independent processes. Constructing pharmacological tools for analyzing $G$ protein signaling pathways, we identified new therapeutic targets (TRPC $3 / 6$ channels, $\mathrm{P}_{2} \mathrm{Y}_{6}$ receptor) for the treatment of heart failure. Further studies using cardiomyocyte-specific conditional knockout mice will establish the importance of these proteins in heart failure. In the future, a better understanding of the components that participate in GPCR signaling pathways in healthy and failing hearts may provide a mechanistic basis for improving heart failure treatment.

\section{Acknowledgments}

This study was supported by grants from Grant-in-Aid for Scientific Research on Innovative Areas and from the Ministry of Education, Culture, Sports, Science, and Technology of Japan.

\section{References}

1 Fitzgibbons TP, Meyer TE, Aurigemma GP. Mortality in diastolic heart failure: an update. Cardiol Rev. 2009;17:51-55.

2 Gudermann T, Nurnberg B, Schultz G. Receptors and G proteins are primary components of transmembrane signal transduction. Part 1. G-protein-coupled receptors: structure and function. J Mol Med. 1995;73:51-63.

3 Tang CM, Insel PA. GPCR expression in the heart; "new" receptors in myocytes and fibroblasts. Trends Cardiovas Med. 2004; 14:94-99.

4 Nishida M, Suda M, Tanabe S, Onohara N, Nakaya M, Kanaho $\mathrm{Y}$, et al. Pertussis toxin upregulates angiotensin type 1 receptors through TLR4-mediated Rac activation. J Biol Chem. 2010; 285:15268-15277.
5 Maruyama Y, Nishida M, Sugimoto Y, Tanabe S, Turner JH, Kozasa $\mathrm{T}$, et al. $\mathrm{G} \alpha_{12 / 13}$ mediate $\alpha 1$-adrenergic receptor-induced cardiac hypertrophy. Circ Res. 2002;91:961-969.

6 Arai K, Maruyama Y, Nishida M, Tanabe S, Kozasa T, Mori Y, et al. Differential requirement of $\mathrm{G} \alpha_{12}, \mathrm{G} \alpha_{13}, \mathrm{G} \alpha_{\mathrm{q}}$, and $\mathrm{G} \beta \gamma$ for endothelin-1-induced c-Jun $\mathrm{NH}_{2}$-terminal kinase and extracellular signal-regulated kinase activation. Mol Pharmacol. 2003;63: 478-488.

7 Nishida M, Maruyama Y, Tanaka R, Kontani K, Nagao T, Kurose H. $\mathrm{G} \alpha_{\mathrm{i}}$ and $\mathrm{G} \alpha_{\mathrm{o}}$ are target proteins of reactive oxygen species. Nature. 2000;408:492-495.

8 Sato M, Cismowski MJ, Toyota E, Smrcka AV, Lucchesi PA, Chilian WM, et al. Identification of a receptor-independent activator of G protein signaling (AGS8) in ischemic heart and its interaction with G $\beta \gamma$. Proc Natl Acad Sci U S A. 2006;103: 797-802.

9 Hippe H-J, Luedde M, Lutz S, Koehler H, Eschenhagen T, Frey $\mathrm{N}$, et al. Regulation of cardiac cAMP synthesis and contractility by nucleoside diphosphate kinase $\mathrm{B} / \mathrm{G}$ protein $\beta \gamma$ dimer complexes. Circ Res. 2007;100:1191-1199.

10 Wettschureck N, Offermanns S. Mammalian G proteins and their cell type specific functions. Physiol Rev. 2005;85:1159-1204.

11 Molkentin JD, Lu JR, Antos CL, Markham B, Richardson J, Robbins J, et al. A calcineurin-dependent transcriptional pathway for cardiac hypertrophy. Cell. 1998;93:215-228.

12 Onohara N, Nishida M, Inoue R, Kobayashi H, Sumimoto H, Sato Y, et al. TRPC3 and TRPC6 are essential for angiotensin IIinduced cardiac hypertrophy. EMBO J. 2006;25:5305-5316.

13 Nishida M, Kurose H. Roles of TRP channels in the development of cardiac hypertrophy. Naunyn Schmiedebergs Arch Pharmacol. 2008;378:395-406.

14 Nishida M, Watanabe K, Sato Y, Nakaya M, Kitajima N, Ide T, et al. Phosphorylation of TRPC6 channels at $\mathrm{Thr}^{69}$ is required for anti-hypertrophic effects of phosphodiesterase 5 inhibition. J Biol Chem. 2010;285:13244-13253.

15 Kiyonaka S, Kato K, Nishida M, Mio K, Numaga T, Sawaguchi $\mathrm{Y}$, et al. Selective and direct inhibition of TRPC3 channels underlies biological activities of a pyrazole compound. Proc Natl Acad Sci U S A. 2009;106:5400-5405.

16 Nishida M, Tanabe S, Maruyama Y, Mangmool S, Urayama K, Nagamatsu Y, et al. $\mathrm{G} \alpha_{12 / 13^{-}}$and reactive oxygen species-dependent activation of c-Jun $\mathrm{NH}_{2}$-terminal kinase and p38 mitogenactivated protein kinase by angiotensin receptor stimulation in rat neonatal cardiomyocytes. J Biol Chem. 2005;280:1843418441.

17 Nishida M, Sato Y, Uemura A, Narita Y, Tozaki-Saitoh H, Nakaya $\mathrm{M}$, et al. $\mathrm{P} 2 \mathrm{Y}_{6}$ receptor- $\mathrm{G} \alpha_{12 / 13}$ signalling in cardiomyocytes triggers pressure overload-induced cardiac fibrosis. EMBO J. 2008; 27:3104-3115.

18 Braun OO, Lu D, Aroonsakool N, Insel PA. Uridine triphosphate (UTP) induces profibrotic responses in cardiac fibroblasts by activation of $\mathrm{P}_{2} \mathrm{Y}_{2}$ receptors. J Mol Cell Cardiol. 2010;49:362-369.

19 Nishida M, Ogushi M, Suda R, Toyotaka M, Saiki S, Kitajima N, et al. Heterologous down-regulation of angiotensin type 1 receptors by purinergic $\mathrm{P}_{2} \mathrm{Y}_{2}$ receptor stimulation through S-nitrosylation of NF- $\kappa$ B. Proc Natl Acad Sci U S A. 2011;108:6662-6667.

20 Post GR, Goldstein D, Thuerauf DJ, Glembotski CC, Brown JH. Dissociation of p44 and p42 mitogen-activated protein kinase activation from receptor-induced hypertrophy in neonatal rat ventricular myocytes. J Biol Chem. 1996;271:8452-8457. 